\title{
Design and Evaluation of Faculty Development Workshop for Teaching, Learning and Assessment Using E-resources in an Indian Medical School
}

\author{
Ramachandran, $K{ }^{1}$ \& Faith, $M .{ }^{2}$
}

\begin{abstract}
Introduction: E learning can enhance educational reform for the computer literate learners by the ease of access to learning material any time and helping them pace their learning curve. It also offers educators a new paradigm based on adult learning principles. We hypothesised to develop, implement and evaluate an E learning Project in Sri Muthukumaran Medical College Hospital \&RI,Chennai, for which Faculty development was crucial. Hence, we designed, implemented and evaluated a capacity building E learning Workshop for faculties of Sri Muthukumaran Medical College Hospital \& RI, Chennai.
\end{abstract}

Methodology: The Workshop on "Teaching, learning and assessment using online Resources" was conducted by an External Faculty Expert and 17 Medical Education Unit (MEU) members were participants, who were trained on various aspects of $E$ learning. They developed $E$ resources for implementation of E learning in Sri Muthukumaran Medical College Hospital \& RI, Chennai. Pre and post tests were conducted. Evaluation of the Workshop was through written feedback obtained from the participants.

Result: Using Wilcoxon singed rank test, there was statistically significant difference between pre and post test score at $p<0.001$ and $112.6 \%$ improvement of scores was observed. An analysis of the feedback questionnaire showed that $76 \%$ of participants felt that the presentation of session on developing E learning Project was outstanding and $24 \%$ felt that it was above average and all of them $(100 \%)$ are encouraged to apply what they have learnt through this session.

Conclusion: The authors conclude that Faculty development Workshops are effective in enabling faculties to develop feasible $E$ learning projects for introduction of $E$ learning for educational reforms.

Keywords: E learning, Faculty development, Workshop

\section{Introduction}

E learning refers to Web-based learning, online learning, distributed learning, computerassisted instruction or Internet-based learning.

${ }^{1}$ Professor \& Head, Department of Anatomy, Sri Muthukumaran Medical College Hospital \& Research Institute, Chennai, Tamil Nadu, India.

Affiliated to the TN DR.MGR Medical University, Chennai.

${ }^{2}$ Professor,Department of Biochemistry, Head, Medical Education Department, Christian Medical College (CMC), Vellore, Tamil Nadu, India.

Affiliated to the TN DR.MGR Medical University, Chennai.

Corresponding Author:

Prof. K. Ramachandran

Department of Anatomy, Sri Muthukumaran Medical College Hospital \& Research Institute, Chennai, Tamil Nadu, India.

Email: kalpanasriram1@gmail.com
It is the use of internet for delivering solutions that leads to increase in knowledge and performance (Ruiz et al., 2006). E learning can lead to enhancement of educational reform for the computer literate learners. Some of the advantages that $E$ learning offers the learners are the increase in access to learning material, ease with which the contents can be updated, learning on the move and just in time information. Also for the faculties it keeps them updated in a dynamic changing learning environment (Vyas et al., 2016). It also offers educators a new paradigm based on adult learning principles according to which adult learners learn by relating new learning to past experiences, linking learning to specific needs, by applying what they have learnt and hence

DOI: http://doi.org/10.4038/seajme.v13i2.211

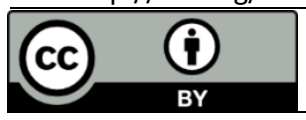

(C) SEAJME. This is an Open Access article distributed under the terms of the Creative Commons Attribution License (http://creativecommons.org/licenses/by/4.0/), which permits unrestricted use, distribution, and reproduction in any medium, provided the original author and source are credited 
results in effective and efficient learning (Ruiz et al., 2006).

The new generation of digital natives coming to medical schools and the faculties who teach them are faced with lot of technological tools and resources which are always on the raise and which are designed to complement their teaching and learning. As these technologies are constantly evolving, they promise exciting opportunities but at the same time both the educators and students face a lot of stress for appropriate and effective usage of technology (Robin et al., 2011).

There are various advantages of $E$ learning such as ease of access and flexible hours, personalised content, pace of learning decided by the student, availability of course content all the time, reduction in cost and time spent by the students, the possibility of training a large number of people at the same time and development of self-study and self-learning capabilities among students. There are also various disadvantages. Though there are criticisms and limitations, what is certain is that when technology is applied to education, it leads to increased knowledge dissemination. Hence in his article Marian et al., concludes that learning using $E$ learning tools is consistent and effective and should be increasingly used in teaching medical students at all levels from Under Graduate to Post Graduate. Incorporation of these tools should be regarded as desirable by those who are involved in medical Education (Mariani et al., 2012).

Our Medical School uses traditional method of Teaching and learning during working hours through didactic Lectures, Practicals, and Clinics.Students have neither access to the learning materials taught in the classroom outside working hours nor can have interactions, discussions with faculties outside working hours (when they can learn at their own pace and time). The students have access to abundant information from various internet sources outside Medical School working hours but the information accessed by them is not tailored to their learning needs/ Curriculum. Also there was a felt need by the students of Sri Muthukumaran Medical College Hospital \& RI, Chennai for introduction of E learning in Sri Muthukumaran Medical College Hospital \& RI, Chennai, based on the needs assessment study conducted earlier in Sri Muthukumaran Medical College Hospital \& RI, Chennai. Hence, there was a need to design, develop and establish an E learning platform in Sri Muthukumaran Medical College Hospital
\& RI, Chennai which will best suit to cater the specific learning needs of students based on their curriculum. This will result in creation of locally relevant resources and this can complement the traditional teaching and learning.

Hence, we hypothesised to develop, implement and evaluate an E learning Project in Sri Muthukumaran Medical College Hospital \& RI, Chennai for introduction of E learning for educational reforms, for which Faculty development was the crucial step. Hence, we designed, implemented and evaluated a capacity building E learning Workshop for faculties of Sri Muthukumaran Medical College Hospital \& RI, Chennai.

\section{Methodology}

Medical Education Unit of Sri Muthukumaran Medical College Hospital \& RI, Chennai organised an one day Faculty development Workshop on "Teaching, learning and assessment using online Resources" conducted by a faculty expert from Christian Medical College (CMC), Vellore, in which 17 participants who are members of Medical Education Unit from various Pre, Para and clinical departments in the ranks of Professor (7 faculties), Associate Professor (7 faculties) and Assistant Professor (3 Faculties) of Sri Muthukumaran Medical College Hospital \& RI, Chennai, were trained on various aspects of $E$ learning such as Introduction to Principles of $E$ learning, its implementation with examples, hurdles and challenges associated with implementation of $\mathrm{E}$ learning in a Medical School and resources available for E learning. Following this, an interactive session was facilitated on how to develop and implement $E$ learning Project in Sri Muthukumaran Medical College Hospital \& RI, Chennai. For this participants were divided in to groups of 4 or 5.The faculty were then asked to develop well defined and specific E-learning resources for students involving their subject. A plenary was conducted in which the participants presented the developed resources pertaining to various specialties. The developed $E$ resources were varied. This included formation of a $G$ mail group for participants of Workshop by group 1 through which a video entailing correct and appropriate way of blood pressure measurement was sent, Development of a Quiz through use of survey monkey by groups 2 and 3 and formation of Whatsapp group for sharing resources by Group 4 ( Table 1). 
Assessment of learning was done by a validated Pre and post-test questionnaire given to participants. Evaluation of the Workshop was through written feedback obtained from the participants at the end of the Workshop.
The results of the Workshops were tabulated and comparisons of Pretest and Post test Scores were statistically analyzed using Wilcoxon Signed Ranks Test (Table 2) to evaluate the effectiveness of the Workshop.

Table 1: E learning Resources developed by Participants

\begin{tabular}{cll}
\hline Group & \multicolumn{1}{c}{ E learning tool used } & \multicolumn{1}{c}{ E resources developed and shared } \\
\hline I & $\begin{array}{l}\text { Formation of Gmail Group for } \\
\text { participants }\end{array}$ & $\begin{array}{l}\text { Video entailing correct and appropriate way } \\
\text { of blood pressure measurement }\end{array}$ \\
II & Survey Monkey & Development of a Quiz in Pharmacology \\
III & Survey Monkey & Development of a Quiz in Physiology \\
IV & Whatsapp group & Case discussion in Medicine \\
\hline
\end{tabular}

An analysis of Feedback questionnaire was done by grouping the responses of participants under the following subheadings.

1. Tabulation of the participant's response on the various sessions by analysing Likert's scale type of questions in the feedback questionnaire (Table 3 ).

2. Factors of the Workshop that was most beneficial.

3. Factors that facilitated learning in the Workshop.

4. Factors that inhibited learning in the Workshop.

5. Learning points achieved by participants through the Workshop.

\section{Results}

The results are summarised as follows.

Assessment of Learning: Analysis of Pre test and Post test Scores

In this study, the Pre-test mean score was $2.35 \pm 1.36$ and the Post-test mean score was $5.0 \pm 0.86$. From table 2, using Wilcoxon Signed rank test, we found statistical significant difference between pre and post test score at $p<0.001$. Pre-test mean is 2.35 \pm 1.36 and post-test mean is $5.0 \pm 0.86$. Nearly $112.6 \%$ improvement of scores was observed, which is statistically significant.

Table 2: Comparison of Pre test \& Post test Scores -Wilcoxon Signed Ranks Test

\begin{tabular}{llccc}
\hline \multicolumn{1}{c}{ Ranks } & N & Mean Rank & Sum of Ranks \\
\hline Pro test - Pre test & Negative ranks & $0^{\mathrm{a}}$ & .00 & .00 \\
& Positive Ranks & $17^{\mathrm{b}}$ & 9.00 & 153.00 \\
& Ties & $0^{\mathrm{c}}$ & & \\
& Total & 17 & & \\
& &
\end{tabular}

a. Post test < Pre test

b. Post test $>$ Pre test

c. Post test $=$ Pre test 


\begin{tabular}{|l|c|}
\hline \multicolumn{1}{|c|}{ Test Statistics } & Pro test - Pre test \\
\hline$Z$ & $-3.658^{\mathrm{a}}$ \\
\hline Asymp. Sig (2-tailed) & .000 \\
\hline \multicolumn{2}{|c|}{ a. Based on negative ranks } \\
b. Wilcoxon signed ranks test
\end{tabular}

Evaluation of the Workshop: Analysis of Feedback Questionnaire

From table $3, \quad$ it is clear that $76 \%$ of participants felt that the presentation of sessions on Introduction to Principles of $E$ learning and the session on developing $E$ learning Project was outstanding and $24 \%$ felt that it was above average. $70 \%$ and $30 \%$ of the participants found the session on $E$ learning in CMC Vellore outstanding and above average respectively. Also $74 \%$ and $26 \%$ of participants found the session on opportunities and challenges in $\mathrm{E}$ learning outstanding and above average respectively.

On the aspects of the Workshop that was most beneficial, the participants responded that the steps in development of an E learning Project, step wise designing of $E$ resources, hands on training given, personal experiences shared by the Expert, step wise explanation of designing
E resources, interactive discussions, hands on activity given were most beneficial .

Also on the factors that facilitated participant's learning in the Workshop were the power points shown, knowledge of resource faculty, feedback given, departmental support on modern technology, clear presentations, interactions, friendly non-threatening learning environment and hands on training given. The factors that inhibited learning in this Workshop were age and difficulty in adapting to the newer technologies used.

The main learning point achieved by the participants were how to develop $E$ learning Projects, effectiveness of $E$ learning, how to use $E$ learning resources effectively, importance of teaching, learning and assessment using technologies, to design and implement $\mathrm{E}$ learning platforms.

Table 3: Analysis of Session Evaluation

\begin{tabular}{lcc}
\hline \multicolumn{1}{c}{ Presentation of Session } & Outstanding (\%) & Above Average (\%) \\
\hline Introduction to Principles of E learning & 76 & 24 \\
E-Learning in Christian Medical College, Vellore & 70 & 30 \\
Opportunities and Challenges & 74 & 26 \\
Developing E-learning projects & 76 & 24 \\
\hline
\end{tabular}

\section{Discussion}

The origin of the term E learning though not certain, it is suggested to have originated during 1980's, with in similar time frame of another delivery mode online learning. Though there is some uncertainty as to what is the exact characteristics of the term, but it is clear that all forms of e- learning, whether it is application, programme, objects, websites etc., it should eventually provide a learning opportunity for individuals (Moore et al., 2011). The term Web based learning is also referred as online learning or e- learning as it comprises of online course materials. In this type of learning it is possible to incorporate discussion forums through $E$ mail, video conferencing and live lectures. Teachers should be stimulated to use web and other information technology in their teaching. This can be done by faculty training and support. Teachers have to be informed of good practices and standards have to be set on how to present the information and also manage learning environments (Mc Kimm et al., 2003).

Integration of E learning as an official standard of education is to be made by faculty's well 
designed plan according to current possibilities. Some Institutions have used this as a standard solution for updating or expanding their curricula, it is always best to begin with a blended strategy that takes in to considerations the benefits and burden of blended learning before revising the curriculum (Masic, 2008). In order to successfully implement $E$ learning one of the important component is Faculty member development (Vyas et al., 2016). Hence, we designed an $\mathrm{E}$ learning Workshop for faculty development for the purpose of developing an E learning platform for its establishment in Sri Muthukumaran Medical College Hospital \& RI, Chennai. It is evident from the results that the Workshop was effective in enhancing the knowledge of the faculties which was evident from the post test scores. In addition, the feedback given by participants showed that the hands on experience given helped them develop short $E$ resources at the end of the Workshop. Since the participants of the Workshop are members of the Medical Education Unit, who will also be core members who will be involved in establishing $E$ learning platform in Sri Muthukumaran Medical College Hospital \& RI, Chennai, it is evident that this Workshop has resulted in increase in their knowledge and skill which will help them train other faculties of Sri Muthukumaran Medical College Hospital \& RI, Chennai who will be the stake holders of the E learning platform. As a follow up to this Workshop after a period of 2 months, a group of faculty members from various departments were identified and a one day Workshop on $E$ learning was conducted for them with hands on experience by these members of Medical Education Unit who were the resource persons. This process will be repeated for all faculty members of Sri Muthukumaran Medical College Hospital \& RI, Chennai so that all faculties in the Institution are trained in all aspects of $E$ learning. This will ensure effective establishment and implementation of $E$ learning platform in Sri Muthukumaran Medical College Hospital \& RI, Chennai, as faculty member development is the crucial step for its implementation. It is evident from the design of the Workshop that the faculties who are trained through the Workshop can replicate their experience to train other faculties in Sri Muthukumaran Medical College Hospital \& RI, Chennai.

In a study done by Vyas et al., a Project based Faculty development Workshop for $E$ learning was conducted for faculties from 13 Medical Colleges in India, in which the participants developed E learning Projects for implementation in their Institution during the Workshop. A one year follow up showed that majority of the Projects (10 out of 13) were implemented "to some extent" or "to a great Extent". Our Workshop is unique in its design in that it is specifically conducted to train a core group of MEU members who were the participants of the Workshop, who in turn trained other faculties of the Institution. This is evident from the successful conduct of a post follow up Workshop by the MEU members for a group of faculties of the Institution. Hence, this Workshop has served as a key stimulus for training of the stake holders of the $E$ learning Project to be implemented in Sri Muthukumaran Medical College Hospital \& RI, Chennai.

In a review of 124 articles on E learning in low and middle income countries (LMIC) by Frehywot et al., the author found that $\mathrm{e}$ learning is utilized and adapted in LMIC countries. The methods of $E$ learning adapted are from digital libraries to more complex distance learning network, multimedia software, Learning Management systems, virtual simulations, mobile applications and other $\mathrm{E}$ resources. The author concludes that using $E$ learning can result in greater educational opportunities for students with increased faculty effectiveness and efficiency. But this requires certain level of Institution readiness in human and infrastructure resources which is not always present in LMICs (Frehywot et al., 2013).

As quoted by Harden RM, E learning can be used for newer methodologies to develop content for Post graduate Medical Education. The developing trends are Instructional design based on reusable learning objects (RLOs) and the semantic web. RLOs are small pieces of a diagram to a combination of such resources (Harden, 2016). Semantic Web, the future of $E$ learning is one which all $E$ learning resources can be linked in some way based on their context (Harden, 2016).

In Graz Medical School, a Virtual Medical Campus was put in place in which the $E$ learning materials developed were tailored to the curricular needs of the students. They have also introduced a participatory design in which $E$ learning experts, faculties and students develop the $E$ content. In this technological support is given by the $E$ learning experts, subject specific expertise is contributed by the teachers and the students design the $\mathrm{E}$ content according to their specific requirements of their learning needs (Smolle, 
2010). In our Medical School there is a need to design, develop and establish an E learning platform which will best suit the specific learning needs of students based on their curriculum. This will result in creation of locally relevant resources and this can complement the traditional teaching and learning. For this the stake holders (Faculties) have to be trained which necessitated the need for conduct of a Workshop to train faculties of Sri Muthukumaran Medical College Hospital \& RI, Chennai with experts from well-established $E$ learning centers outside. Hence, a capacity building Workshop for faculties was conducted. It is evident from the feedback received from the participants of this Workshop that the Workshop has resulted in increase in their knowledge and skill which will help them train other faculties of Sri Muthukumaran Medical College Hospital \& RI, Chennai who will be the stake holders of the $E$ learning platform which will be established in Sri Muthukumaran Medical College Hospital \& RI, Chennai.

\section{Conclusion}

The authors conclude that Faculty development Workshops are effective in enabling faculties to develop feasible $E$ learning projects for introduction of $E$ learning for educational reforms and this will enhance the effectiveness of subsequent implementation of the Project.

\section{Conflict of Interest}

The authors declare no conflict of interest.

\section{References}

Frehywot, S., Vovides, Y., Talib, Z., Mikhail, N., Ross, H., Wohltjen, H., Bedada, S., Korhumel, K., Koumare, A.K. and Scott, J. (2013) E- learning in medical education in resource constrained low-and middle-income countries. Human resources for health, 11, 1, pp.4.

Harden, R.M. (2006) Trends and the future of postgraduate medical education. Emergency medicine journal, 23, 10, pp.798-802.

Mariani, A.W., Terra, R.M. and Pêgo-Fernandes, P.M. (2012) E-Learning: from useful to indispensable tool. Sao Paulo Medical Journal, 130, 6, pp.357-359.

Masic, I. (2008) E-learning as new method of medical education. Acta informatica medica, 16, 2, pp.102.

McKimm, J., Jollie, C. and Cantillon, P. (2003) Web based learning. Bmj, 326, 7394, pp.870-873.

Moore, J.L., Dickson-Deane, C. and Galyen, K. ((2011) E-Learning, online learning, and distance learning environments: Are they the same?. The Internet and Higher Education, 14, 2, pp.129135.

Robin, B.R., McNeil, S.G., Cook, D.A., Agarwal, K.L. and Singhal, G.R. (2011) Preparing for the changing role of instructional technologies in medical education. Academic Medicine, 86, 4, pp.435-439.

Ruiz, J.G., Mintzer, M.J. and Leipzig, R.M. (2006) The impact of e-learning in medical education. Academic medicine, 81, 3, pp.207-212.

Smolle, J. (2010) Virtual medical campus: the increasing importance of E-learning in medical education. Tijdschrift voor Medisch Onderwijs, 29, 1, pp.42-47.

Vyas, R., Faith, M., Selvakumar, D., Pulimood, A. and Lee, M. (2016) Project-based faculty development for e-learning. The clinical teacher, 13, 6, pp.405-410. 